n.tronos

glyndîn

Glyndŵr University

Glyndŵr University Research Online

Chemistry

Materials Science

$1-1-2003$

\title{
Tricarbonylrhenium(I) halide complexes of chiral non-racemic 2-(dioxolanyl)-(dioxanyl)pyridine ligands: synthesis, NMR and DFT calculations.
}

Peter J. Heard

Glyndwr University, p.heard@glyndwr.ac.uk

Paul M. King

Phunrawie Sroisuwan

Nikolas Kaltsoyannis

Follow this and additional works at: http://epubs.glyndwr.ac.uk/chem

Part of the Inorganic Chemistry Commons, Organic Chemistry Commons, and the Physical Chemistry Commons

This is the author's final version of the work after peer review. This article was originally published in the Polyhedron Journal in 2003 by Elsevier. The published article can be found at http://www.sciencedirect.com

\section{Recommended Citation}

Heard, P. J., King, P. M., Sroisuwan, P., \& Kaltsoyannis, N. (2003) 'Tricarbonylrhenium(I) halide complexes of chiral non-racemic 2-(dioxolanyl)-(dioxanyl)pyridine ligands: synthesis, NMR and DFT calculations'. Polyhedron, 22 (25-26), 3371-3378

This Article is brought to you for free and open access by the Materials Science at Glyndwir University Research Online. It has been accepted for inclusion in Chemistry by an authorized administrator of Glyndŵr University Research Online. For more information, please contact 


\section{Introduction}

Chiral non-racemic $C_{2}$-symmetric N/N/N tridentate ligands, such as 2,6-bis(oxazolinyl)pyridines have been used extensively as auxiliary ligands in both stoichiometric and catalytic transition metal-mediated enantioselective organic transformations [1]. When such ligands are restricted to a bidentate bonding mode, the ligands undergo a dynamic stereochemical rearrangement that leads to the exchange of co-ordinated and pendant donor groups $[2,3]$. The chiral centres on the ligands provide an excellent spectroscopic handle on the stereodynamics, allowing the fluxional pathway to be determined unambiguously.

Recently, as part of our ongoing researches on fluxionality in 'chiral-at-ligand' organo-transition metal

\footnotetext{
${ }^{*}$ Corresponding author. Tel.: +44-20-7679-7480; fax: +40-20-76797464.

E-mail address: p.heard@bbk.ac.uk (P.J. Heard).
}

complexes, we reported on the tricarbonylhalogenorhenium(I) complexes of the O/N/O hybrid ligands 2,6bis[(4R,5R)-4,5-dimethyl-1,3-dioxolan-2-yl]pyridine $\left(\mathrm{L}^{1}\right)$ [4] and 2,6-bis[(4R,6R)-4,6-dimethyl-1,3-dioxan-2-yl] pyridine $\left(\mathrm{L}^{2}\right)[5]$ (Fig. 1). These complexes undergo three dynamic processes; namely a flip of the co-ordinated acetal ring and exchange of the co-ordinated and pendant acetal rings via tick-tock and rotation mechanisms $[4,5]$. The size of the acetal ring [five-membered (dioxolanyl) or six-membered (dioxanyl)] has opposite effects on the relative energies of ring flip and tick-tock processes: $\Delta G^{\ddagger}$ for the ring flip process is lowered on substitution of $\mathrm{L}^{1}$ for $\mathrm{L}^{2}$, while that for the tick-tock exchange increases. The reasons for this were not obvious and we therefore chose to investigate the analogous complexes of the mixed acetal ligand 2 -[( $4 R, 5 R)-4,5$-dimethyl-1,3-dioxolan-2-yl]-6-[(4R,6R)-4,6-dimethyl-1,3dioxan-2-yl]pyridine $\left(\mathrm{L}^{\mathrm{HH}}\right)$ in an attempt to gain further insights on the problem. The results of this study are reported here. 
<smiles>C[C@@H]1OC(c2cccc(C3O[C@H](C)[C@@H](C)O3)n2)O[C@@H]1C</smiles><smiles>C[C@H]1OC(c2ccccn2)O[C@@H]1C</smiles><smiles>CC1C(OC2CC2(C)C)OC1c1ccccn1</smiles>

$\mathrm{L}^{4}$

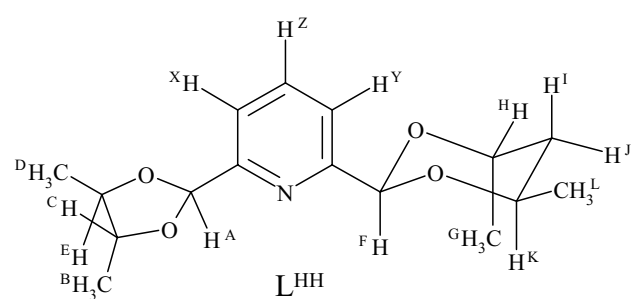<smiles>[2H]C1(c2cccc(C3OC4CC(C)C(C4)O3)n2)OC(C)C(C)O1</smiles>

Fig. 1. The chrial non-racemic ligands $\mathrm{L}^{1}, \mathrm{~L}^{2}, \mathrm{~L}^{3}, \mathrm{~L}^{4}, \mathrm{~L}^{\mathrm{HH}}$ and $\mathrm{L}^{\mathrm{HD}}$, showing the hydrogen atom labelling for $\mathrm{L}^{\mathrm{HH}}$.

\section{Results}

56

\subsection{The ligands}

2-[(4R,5R)-4,5-dimethyl-1,3-dioxolan-2-yl]-6-[(4R,6R)58 4,6-dimethyl-1,3-dioxan-2-yl]Pyridine $\left(\mathrm{L}^{\mathrm{HH}}\right)$ was syn59 thesised from 2,6-dibromopyridine, as shown in Scheme 60 1, and characterised by mass spectrometry and NMR: 61 data are reported in Tables 1 and 2. Both routes give 62 similar overall yields. During the work-up of $(\mathbf{3 a} / \mathbf{3 b})$, the 63 attached acetal ring can be cleaved by hydrochloric acid, 64 used in the work-up, yielding a small amount of 2,665 pyridinedicarboxaldehyde. Route (i) is thus the pre66 ferred pathway: $(2 R, 3 R)$-butane-2,3-diol is the cheaper 67 of the diols.

68 The ${ }^{1} \mathrm{H}$ NMR spectrum of $\mathrm{L}^{\mathrm{HH}}$ is fully and unam69 biguously assignable. The acetal- $\mathrm{C}$ hydrogens, $\mathrm{H}_{\mathrm{A}}$ (di70 oxolanyl) and $\mathrm{H}_{\mathrm{F}}$ (dioxanyl) (see Fig. 1 for hydrogen 71 atom labelling), are identified by their low frequency 72 shifts (ca. $\delta 6.0$ ) and differentiated by a NOESY ex73 periment. $\mathrm{H}_{\mathrm{A}}$ undergoes cross-relaxation with $\mathrm{Me}_{\mathrm{B}}$ and $74 \mathrm{H}_{\mathrm{E}}$, which are assigned to the dioxolanyl ring on the 75 basis of their scalar couplings, while $\mathrm{H}_{\mathrm{F}}$ undergoes cross-relaxation with $\mathrm{H}_{\mathrm{L}}$ and $\mathrm{Me}_{\mathrm{G}}$, of the dioxanyl ring. The NOEs observed between $\mathrm{H}_{\mathrm{F}}$ and $\mathrm{H}_{\mathrm{L}}$, and $\mathrm{H}_{\mathrm{F}}$ and $\mathrm{Me}_{\mathrm{G}}$ are consistent with the dioxanyl ring adopting a chair configuration with the pyridine ring equatorial. The full $\mathrm{AB}_{3} \mathrm{CD}_{3} \mathrm{E}$ and $\mathrm{AB}_{3} \mathrm{CDEFG}_{3}$ spin systems of the dioxolanyl and dioxanyl rings were analysed (noniteratively) using the program GNMR [6]. The 3- and 5position hydrogens of the pyridine ring, $\mathrm{H}_{X}$ and $\mathrm{H}_{Z}$, are distinguished by virtue of the fact that they undergo cross-relaxation with the acetal- $\mathrm{C}$ hydrogens, $\mathrm{H}_{\mathrm{A}}$ and $\mathrm{H}_{\mathrm{F}}$, respectively. The ${ }^{13} \mathrm{C}$ NMR spectrum was assigned on the basis of signal chemical shifts, DEPT experiments and by comparison with the spectra obtained [7] for $\mathrm{L}^{1}, \quad \mathrm{~L}^{2}, \quad 2-[(4 R, 5 R)-4,5$-dimethyl-1,3-dioxolan-2yl]pyridine $\left(\mathrm{L}^{3}\right)[8]$ and $2-[(4 R, 6 R)-4,6$-dimethyl-1,3-dioxan-2-yl] pyridine $\left(\mathrm{L}^{4}\right)$ [5]. NMR data are reported in Table 2.

The deuterium labelled analogues of $\mathrm{L}^{\mathrm{HH}}$, namely 2[(4R,5R)-4,5-dimethyl-1,3-dioxolan-2-deuteryl]-6-[(4R,6R) -4,6-dimethyl-1,3-dioxan-2-yl]pyridine $\left(\mathrm{L}^{\mathrm{DH}}\right)$ and 2-[(4R, $5 R)$-4,5-dimethyl-1,3-dioxolan-2-deuteryl]-6-[(4R,6R)-4,6dimethyl-1,3-dioxan-2-deuteryl]pyridine $\left(\mathrm{L}^{\mathrm{DD}}\right)$ were prepared similarly, using $\mathrm{d}_{7}$-dimethylformamide in the 


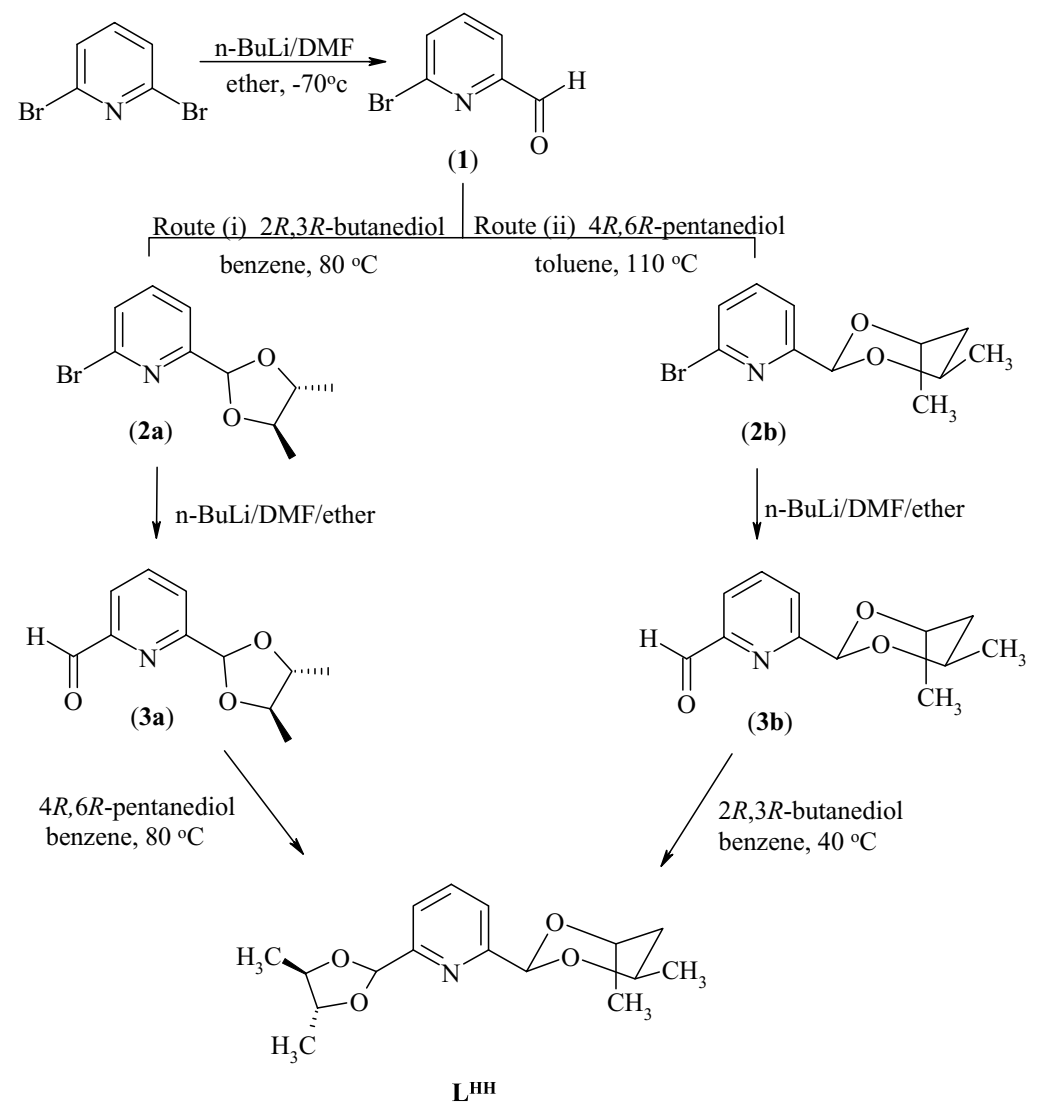

Scheme 1 .

99 appropriate step(s) (Scheme 1), and identified by mass 100 spectrometry and NMR: data are reported in Tables 1

101 and 2. The selective deuteration of the dioxolanyl ring 102 (synthesis of $\mathrm{L}^{\mathrm{DH}}$ ) is best achieved by reaction of 2-

103 deuteraldehyde-6-[(4R,6R)-4,6-dimethyl-1,3-dioxan-2-

104 deuteryl]pyridine with $(2 R, 3 R)$-butane-2,3-diol [i.e., route (ii), Scheme 1]. This route gives the best overall 105 yield of $\mathrm{L}^{\mathrm{DH}}$ and minimises the amount of 2-[(4R,5R)- 106 4,5-dimethyl-1,3-dioxolan-2-yl]-6-[(4R,6R)-4,6-dimethyl- 107 1,3-dioxan-2-deuteryl]pyridine $\left(\mathrm{L}^{\mathrm{HD}}\right)$, which is produced 108 as a side product: careful control of the reaction con- 109 ditions enabled $\mathrm{L}^{\mathrm{DH}}$ to be isolated in $80 \%$ excess over 110

Table 1

Analytical data for $\mathrm{L}^{\mathrm{HH}}, \mathrm{L}^{\mathrm{DH}}$ and $\mathrm{L}^{\mathrm{DD}}$, and the complexes $\left[\operatorname{ReX}(\mathrm{CO})_{3}(\mathrm{~L})\right]\left(\mathrm{L}=\mathrm{L}^{\mathrm{HH}}, \mathrm{X}=\mathrm{Cl}, \mathrm{Br}\right.$ or $\left.\mathrm{I}\right)$ and $\left[\operatorname{ReBr}(\mathrm{CO})_{3}\left(\mathrm{~L}^{\mathrm{HD}}\right)\right]$

\begin{tabular}{|c|c|c|c|c|c|c|c|}
\hline \multirow[t]{2}{*}{ Ligand/Complex } & \multirow{2}{*}{$\begin{array}{l}\text { Reaction } \\
\text { time (h) }\end{array}$} & \multirow[t]{2}{*}{ Yield $(\%)$} & \multirow[t]{2}{*}{$v(\mathrm{CO})^{\mathrm{a}}\left(\mathrm{cm}^{-1}\right)$} & \multirow[t]{2}{*}{ Mass spectral data } & \multicolumn{3}{|l|}{ Analyses $^{\mathrm{b}}(\%)$} \\
\hline & & & & & $\mathrm{C}$ & $\mathrm{H}$ & $\mathrm{N}$ \\
\hline $\mathrm{L}^{\mathrm{HH}}$ & & & & $\begin{array}{l}316[\mathrm{M}+\mathrm{Na}]^{+} \\
294[\mathrm{M}+\mathrm{H}]^{+}\end{array}$ & & & \\
\hline $\mathrm{L}^{\mathrm{DH}}$ & & & & $\begin{array}{l}317[\mathrm{M}+\mathrm{Na}]^{+} \\
295[\mathrm{M}+\mathrm{H}]^{+}\end{array}$ & & & \\
\hline $\mathrm{L}^{\mathrm{DD}}$ & & & & $\begin{array}{l}318[\mathrm{M}+\mathrm{Na}]^{+} \\
296[\mathrm{M}+\mathrm{H}]^{+}\end{array}$ & & & \\
\hline$\left[\mathrm{ReCl}(\mathrm{CO})_{3}\left(\mathrm{~L}^{\mathrm{HH}}\right)\right]$ & 24 & 79 & 1904; 1917; 2031 & $\begin{array}{l}599[\mathrm{M}]^{+} \\
564[\mathrm{M}-\mathrm{Cl}]^{+}\end{array}$ & $37.24(38.09)$ & $3.72(3.87)$ & $2.18(2.34)$ \\
\hline$\left[\operatorname{ReBr}(\mathrm{CO})_{3}\left(\mathrm{~L}^{\mathrm{HH}}\right)\right]$ & 72 & 62 & $1905 ; 1919 ; 2031$ & $\begin{array}{l}643[\mathrm{M}]^{+} \\
564[\mathrm{M}-\mathrm{Br}]^{+}\end{array}$ & $36.65(35.46)$ & $3.64(3.60)$ & $2.39(2.18)$ \\
\hline$\left[\operatorname{ReI}(\mathrm{CO})_{3}\left(\mathrm{~L}^{\mathrm{HH}}\right)\right]$ & 96 & 68 & 1909; 1920; 2031 & $\begin{array}{l}691[\mathrm{M}]^{+} \\
564[\mathrm{M}-\mathrm{I}]^{+}\end{array}$ & 34.57 (33.05) & $3.53(3.36)$ & $2.32(2.03)$ \\
\hline$\left[\operatorname{ReBr}(\mathrm{CO})_{3}\left(\mathrm{~L}^{\mathrm{DH}}\right)\right]$ & 72 & 51 & 1906; 1919; 2031 & $\begin{array}{l}644[\mathrm{M}]^{+} \\
565[\mathrm{M}-\mathrm{Br}]^{+}\end{array}$ & $32.94(35.41)$ & $3.41(3.44)$ & $1.85(2.17)$ \\
\hline
\end{tabular}

Yield reported relative to the $\left[\mathrm{ReX}(\mathrm{CO})_{5}\right]$ compounds.

${ }^{a}$ Infrared data. Spectra recorded in $\mathrm{CH}_{2} \mathrm{Cl}_{2}$ solution.

${ }^{\mathrm{b}}$ Calculated values in parentheses. Poor analytical figures due to impurities, which could not be separated (see text). 
Table 2

NMR data ${ }^{\mathrm{a}} \mathrm{L}^{\mathrm{HH}}$

\begin{tabular}{|c|c|c|c|c|}
\hline \multirow[t]{2}{*}{ Assignment $^{\mathrm{b}}$} & \multicolumn{2}{|c|}{${ }^{1} \mathrm{H}$ NMR data } & \multirow[t]{2}{*}{ Assignment } & \multirow{2}{*}{$\frac{{ }^{13} \mathrm{C} \text { NMR data }}{\delta}$} \\
\hline & $\delta$ & Scalar couplings $(\mathrm{Hz})$ & & \\
\hline $\mathrm{H}_{\mathrm{A}}$ & $6.01(6.0)^{\mathrm{b}}$ & & $\mathrm{CH}_{3}$ & 16.9 \\
\hline $\mathrm{H}_{\mathrm{B}}$ & 1.34 & $J_{\mathrm{BC}} 6.1 ; J_{\mathrm{BE}} 0.1$ & $\mathrm{CH}_{3}$ & 17.0 \\
\hline $\mathrm{H}_{\mathrm{C}}$ & 3.80 & $J_{\mathrm{CD}} 0.1 ; J_{\mathrm{CE}} 7.6$ & $\mathrm{CH}_{3}$ & 17.3 \\
\hline $\mathrm{H}_{\mathrm{D}}$ & 1.38 & $J_{\mathrm{DE}} 6.1$ & $\mathrm{CH}_{3}$ & 21.9 \\
\hline $\mathrm{H}_{\mathrm{E}}$ & 3.84 & & $\mathrm{CH}_{2}$ & 36.8 \\
\hline $\mathrm{H}_{\mathrm{F}}$ & $5.95(5.9)^{\mathrm{c}}$ & & $\mathrm{CHCH}_{3}$ (dioxanyl ring) & 68.1 \\
\hline $\mathrm{H}_{\mathrm{G}}$ & 1.50 & $J_{\mathrm{GH}} 6.9$ & $\mathrm{CHCH}_{3}$ (dioxanyl ring) & 68.8 \\
\hline $\mathrm{H}_{\mathrm{H}}$ & 4.49 & $J_{\mathrm{HI}} 6.1 ; J_{\mathrm{HJ}} 1.0$ & $\mathrm{CHCH}_{3}$ (dioxolanyl ring) & 78.8 \\
\hline $\mathrm{H}_{\mathrm{I}}$ & 2.02 & $J_{\mathrm{IJ}} 13.3 ; J_{\mathrm{IK}} 11.7$ & $\mathrm{CHCH}_{3}$ (dioxolanyl ring) & 80.4 \\
\hline $\mathrm{H}_{\mathrm{J}}$ & 1.45 & $J_{\mathrm{JK}} 2.4$ & acetal- $C$ (dioxanyl ring) & $94.8(25)^{\mathrm{d}}$ \\
\hline $\mathrm{H}_{\mathrm{K}}$ & 4.24 & $J_{\mathrm{KL}} 6.2$ & acetal- $C$ (dioxolanyl ring) & $102.0(25)^{\mathrm{e}}$ \\
\hline $\mathrm{H}_{\mathrm{L}}$ & 1.27 & & pyridine- $\mathrm{C}$ & $\begin{array}{l}120.3 ; 121.2 ; 137.7 ; 156.7^{\mathrm{f}} \\
157.3^{\mathrm{f}}\end{array}$ \\
\hline $\mathrm{H}_{\mathrm{X}}$ & 7.79 & & & \\
\hline $\mathrm{H}_{\mathrm{Y}}$ & 7.66 & $J_{\mathrm{XY}} 7.8 ; J_{\mathrm{XZ}} 7.7$ & & \\
\hline $\mathrm{H}_{\mathrm{Z}}$ & 7.58 & $J_{\mathrm{YZ}} 1.1$ & & \\
\hline
\end{tabular}

$111 \mathrm{~L}^{\mathrm{HD}}$. Attempts to prepare $\mathrm{L}^{\mathrm{HD}}$ were less successful: $\mathrm{L}^{\mathrm{HD}}$ 112 could not be prepared cleanly.

\section{2.2. Complexes}

114 The complexes, $\left[\operatorname{ReX}(\mathrm{CO})_{3} \mathrm{~L}\right]\left(\mathrm{L}=\mathrm{L}^{\mathrm{HH}}, \mathrm{X}=\mathrm{Cl}, \mathrm{Br}\right.$ 115 or $\mathrm{I} ; \mathrm{L}=\mathrm{L}^{\mathrm{DH}}, \mathrm{X}=\mathrm{Br}$ ) were prepared by refluxing the $116\left[\operatorname{ReX}(\mathrm{CO})_{5}\right]$ compounds with a small excess of the ap117 propriate ligand in chloroform. The complexes were 118 isolated as air-stable, microcrystalline solids, soluble in 119 common organic solvents. The infrared spectra of the 120 complexes each displayed three bands in the carbonyl 121 stretching region, characteristic of a fac-octahedral co122 ordination geometry for the $\left[\operatorname{Re}(\mathrm{CO})_{3}\right]$ moiety [9], indi123 cating the potentially terdenate ligands are binding in 124 the expected N/O bidentate fashion. The FAB mass 125 spectra of the complexes each display low intensity 126 peaks due to the molecular ions, $[\mathrm{M}]^{+}$, and high inten127 sity peaks due to the species $[\mathrm{M}-\text { halogen }]^{+}$. The poor 128 analytical figures obtained, particularly for [Re$\left.129 \mathrm{Br}(\mathrm{CO})_{3} \mathrm{~L}^{\mathrm{DH}}\right]$, result from the presence of impurities, 130 which are evidenced in the NMR spectra. Analytical 131 data are reported in Table 1.

132 Assuming that inversion of configuration at the co133 ordinated oxygen atom is rapid [10], the $\left[\operatorname{ReX}(\mathrm{CO})_{3} \mathrm{~L}\right]$ $134\left(\mathrm{~L}=\mathrm{L}^{\mathrm{HH}}\right.$ or $\left.\mathrm{L}^{\mathrm{DH}}\right)$ complexes possess six chiral cen135 tres: the 4- and 5-positions of the dioxolanyl ring, the 136 4- and 6-positions of the dioxanyl ring, the acetal137 carbon atom of co-ordinated acetal ring, and the 138 metal centre. The configuration at 4- and 5-, and 4139 and 6-acetal ring positions are fixed (R), but the configurations at the acetal-carbon and the metal can be $\mathrm{R}$ or $\mathrm{S}$. Thus, there are eight possible diastereoisomers, namely $\mathrm{RR}^{5}, \mathrm{RS}^{5}, \mathrm{SR}^{5}, \mathrm{SS}^{5}, \mathrm{RR}^{6}, \mathrm{RS}^{6}, \mathrm{SR}^{6}$ and $\mathrm{SS}^{6}$, depending on the configuration at the metal and at the co-ordinated acetal-carbon, respectively. The numbers refer to which acetal ring [dioxolanyl (5) or dioxanyl (6)] is co-ordinated (Fig. 2). The configuration at the metal is defined by viewing the metal down the pseudo $C_{3}$ axis of symmetry, with the three $\mathrm{CO}$ groups down, and assigning priorities to the three remaining ligands according to the Cahn-IngoldPrelog system [11].

The ambient temperature solution ${ }^{1} \mathrm{H}$ NMR spectra of the $\left[\mathrm{ReX}(\mathrm{CO})_{3} \mathrm{~L}^{\mathrm{HH}}\right]$ complexes are highly complex due to the overlapping sub-spectra of at least 3 of the 8 possible diastereoisomers (although exchange is slow on the NMR time scale, the diastereoisomers interconvert in solution, frustrating attempts to separate them $[4,5,8])$. The acetal- $\mathrm{CH}$ region, which is most amenable to analysis, displays three pairs of singlets; each diastereoisomer gives rise to two acetal- $\mathrm{CH}$ signals. Additional weak signals that may be due to the presence of minor diastereoisomers or impurities are also observed. The intensities of these additional signals vary, depending on the reaction conditions and the method of purification, suggesting they are more likely to be due to impurities. The assignment of the acetal$\mathrm{CH}$ signals to the dioxolanyl and dioxanyl rings was done on the basis of their spin-lattice relaxation times. Extensive $T_{1}$ measurements [7] on ligands $\mathrm{L}^{1}-\mathrm{L}^{4}$ and their tricarbonylhalogenorhenium(I) complexes indicate 


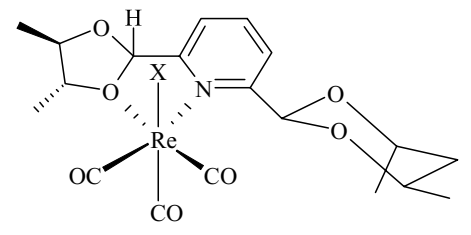

$\mathrm{RS}^{5}$

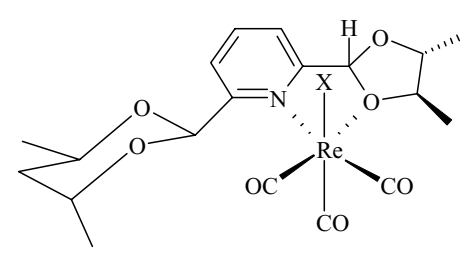

$\mathrm{SR}^{5}$

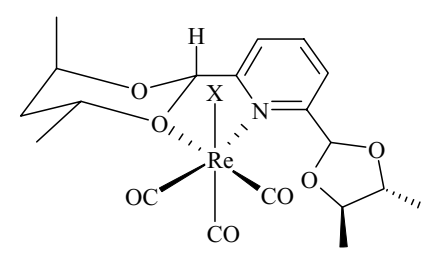

$\mathrm{RS}^{6}$

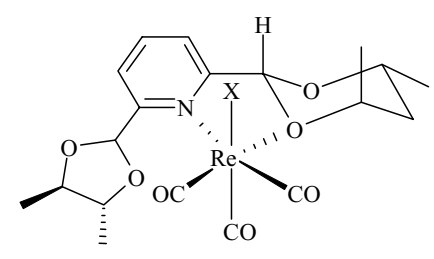

$\mathrm{SR}^{6}$

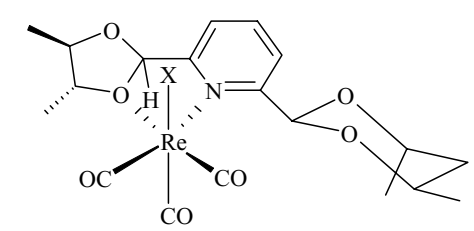

$\mathrm{RR}^{5}$

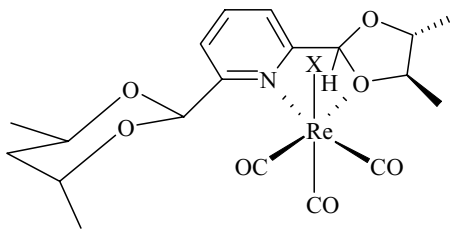

$\mathrm{SS}^{5}$

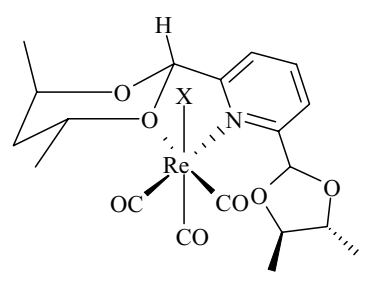

$\mathrm{RR}^{6}$

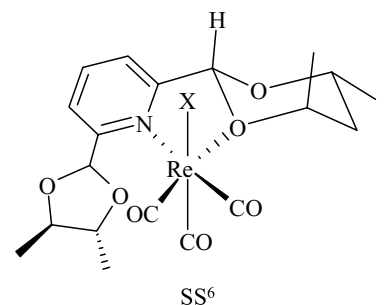

Fig. 2. The eight possible diastereoisomers of the complexes $\left[\mathrm{ReX}(\mathrm{CO})_{3} \mathrm{~L}\right] \mathrm{X}=\mathrm{Cl}, \mathrm{Br}$ or $\mathrm{I} ; \mathrm{L}=\mathrm{L}^{\mathrm{HH}}$ or $\left.\mathrm{L}^{\mathrm{DH}}\right)$. Letters refer to the configuration at the metal and at the acetal-carbon atom of the co-ordinated ring.

171 that the relaxation times for the dioxolanyl-CH's are 172 between ca. 2.4 and $3.2 \mathrm{~s}$, while those for the dioxanyl$173 \mathrm{CH}$ are between ca. 1.0 and $1.5 \mathrm{~s}$; as might be expected, 174 the relaxation times in the free ligands are generally 175 longer then those in the complexed ligands. The re176 laxation times of $\mathrm{H}_{\mathrm{A}}$ (dioxolanyl) and $\mathrm{H}_{\mathrm{F}}$ (dioxanyl) of 177 free $\mathrm{L}^{\mathrm{HH}}$ are ca. 2.5 and $1.0 \mathrm{~s}$, respectively. The pairs of 178 acetal- $\mathrm{CH}$ signals in the $\left[\mathrm{ReX}(\mathrm{CO})_{3} \mathrm{~L}^{\mathrm{HH}}\right]$ complexes 179 also possess $T_{1}$ values of ca. 2.5 and $1.0 \mathrm{~s}$ (Table 3 ) and 180 are thus assigned to the dioxolanyl and dioxanyl rings, 181 respectively. The ${ }^{1} \mathrm{H}$ NMR spectrum of [Re$\left.182 \mathrm{Br}(\mathrm{CO})_{3} \mathrm{~L}^{\mathrm{DH}}\right]$ confirms the assignment. The sub-spectra 183 due to the acetal-ring- and pyridine-hydrogens are also 184 consistent with the presence of three main diastereoi185 somers, but the extensive overlap of signals frustrated 186 attempts to analyse the spectra fully in these regions. $187{ }^{1} \mathrm{H}$ NMR data for the acetal-C hydrogens are reported 188 in Table 3.
It is not possible to determine which of the eight possible diastereoisomers are observed in solution from the NMR spectra. Quantum chemical (DFT) calculations (Table 4) show clearly that co-ordination of the dioxolanyl ring is favoured strongly over the dioxanyl ring. The relative stabilities of the diastereoisomers are in the order $\mathrm{SR}^{5}>\mathrm{RR}^{5}>\mathrm{SS}^{5} \approx \mathrm{RS}^{5}>\mathrm{RS}^{6}>\mathrm{SS}^{6}>$ $\mathrm{RR}^{6}>\mathrm{SR}^{6}$, suggesting that the three solution-state species are $\mathrm{SR}^{5}, \mathrm{RR}^{5}$ and either $\mathrm{SS}^{5}$ or $\mathrm{RS}^{5}$. This is in accord with trends observed previously in the complexes $\left[\mathrm{ReX}(\mathrm{CO})_{3} \mathrm{~L}^{1}\right] \quad(\mathrm{SR}>\mathrm{RR}>\mathrm{SS}>\mathrm{RS}) \quad[4]$ and $[\mathrm{Re}-$ $\mathrm{X}(\mathrm{CO})_{3} \mathrm{~L}^{3}$ ] $(\mathrm{SR}>\mathrm{RR}>\mathrm{RS}>\mathrm{SS})$ [8]. The reasons for the calculated trend are not obvious; however, the amount by which the ligand is destabilised on binding appears to at least play a role. Single point energy calculations were performed on the ligand in each of its bound geometries (the geometry being that taken from the DFT optimisations) and compared to that of the free 
Table 3

${ }^{1} \mathrm{H}$ NMR data ${ }^{\mathrm{a}}$ for the $\left[\mathrm{ReX}(\mathrm{CO})_{3}(\mathrm{~L})\right]\left(\mathrm{L}=\mathrm{L}^{\mathrm{HH}}, \mathrm{X}=\mathrm{Cl}\right.$, Br or I; $\mathrm{L}=\mathrm{L}^{\mathrm{DH}}, \mathrm{X}=\mathrm{Br}$ ) complexes

\begin{tabular}{llll}
\hline Compound & Diastereoisomer & \multicolumn{2}{l}{$\delta$ (acetal-CH $^{\mathrm{c}}$} \\
\cline { 3 - 4 } & & $\mathrm{H}_{\mathrm{A}}$ & $\mathrm{H}_{\mathrm{F}}$ \\
\hline$\left[\operatorname{ReCl}(\mathrm{CO})_{3}\left(\mathrm{~L}^{\mathrm{HH}}\right)\right]$ & $\mathbf{A}(60)$ & $6.37(2.6)$ & $6.55(1.1)$ \\
& $\mathbf{B}(34)$ & $6.81(2.4)$ & $6.45(1.2)$ \\
& $\mathbf{C}(6)$ & $6.62^{\mathrm{f}}$ & $6.10(1.2)$ \\
{$\left[\operatorname{ReBr}(\mathrm{CO})_{3}\left(\mathrm{~L}^{\mathrm{HH}}\right)\right]$} & $\mathbf{A}(54)$ & $6.37(2.6)$ & $6.51(1.0)$ \\
& $\mathbf{B}(43)$ & $6.83(2.4)$ & $6.43(1.2)$ \\
& $\mathbf{C}(3)$ & $6.57^{\mathrm{d}}$ & $6.08(1.2)$ \\
{$\left[\operatorname{ReI}(\mathrm{CO})_{3}\left(\mathrm{~L}^{\mathrm{HH}}\right)\right]$} & $\mathbf{A}(64)$ & $6.34(2.4)$ & $6.40(1.0)$ \\
& $\mathbf{B}(26)$ & $6.76(2.4)$ & $6.38(1.2)$ \\
& $\mathbf{C}(10)$ & $6.57(2.5)$ & $6.05(1.2)$ \\
{$\left[\operatorname{ReBr}(\mathrm{CO})_{3}\left(\mathrm{~L}^{\mathrm{DH}}\right)\right]$} & $\mathbf{A}(60)$ & & $6.51(1.0)$ \\
& $\mathbf{B}(32)$ & & $6.43(1.2)$ \\
& $\mathbf{C}(8)$ & & $6.08(1.2)$ \\
\hline
\end{tabular}

${ }^{\mathrm{a}}$ Recorded in $\mathrm{CDCl}_{3}$ solution at $298 \mathrm{~K}$; chemical shifts quoted relative to tetramethylsilane.

${ }^{\mathrm{b}}$ Populations (\%) given in parentheses.

${ }^{\mathrm{c}}$ Spin lattice relaxation times, measured at $273 \mathrm{~K}$, given in parentheses.

${ }^{\mathrm{d}} T_{1}$ not measured due to overlap signals arising from minor impurities.

Table 4

Calculated energies for the complex $\left[\mathrm{ReCl}(\mathrm{CO})_{3} \mathrm{~L}^{\mathrm{HH}}\right]$

\begin{tabular}{lc}
\hline Diastereoisomer & $E_{\text {rel }}^{\mathrm{b}}\left(\mathrm{kJ} \mathrm{mol}^{-1)}\right.$ \\
\hline $\mathrm{SR}^{5}$ & 0 \\
$\mathrm{RR}^{5}$ & 9 \\
$\mathrm{SS}^{5}$ & 15 \\
$\mathrm{RS}^{5}$ & 15 \\
$\mathrm{RS}^{6}$ & 28 \\
$\mathrm{SS}^{6}$ & 32 \\
$\mathrm{RR}^{6}$ & 39 \\
$\mathrm{SR}^{6}$ & 50 \\
\hline
\end{tabular}

${ }^{\mathrm{a}}$ See Fig. 2 for labelling.

${ }^{\mathrm{b}}$ Relative energy.

207 ligand. The results (Table 5) indicate that the ligand is

208 destabilised on binding; the amount by which the ligand

209 is destabilised follows the trend $\mathrm{SR}^{5}<\mathrm{RR}^{5}<\mathrm{RS}^{5}<$
Table 5

Calculated energies for isolated ligand, $\mathrm{L}^{\mathrm{HH}}$

\begin{tabular}{lc}
\hline Ligand geometry & $E_{\mathrm{rel}}^{\mathrm{b}}\left(\mathrm{kJ} \mathrm{mol}^{-1}\right)$ \\
\hline Free ligand & 0 \\
$\mathrm{SR}^{5}$ & 33 \\
$\mathrm{RR}^{5}$ & 37 \\
$\mathrm{RS}^{5}$ & 40 \\
$\mathrm{SS}^{5}$ & 41 \\
$\mathrm{RS}^{6}$ & 45 \\
$\mathrm{SS}^{6}$ & 45 \\
$\mathrm{RR}^{6}$ & 49 \\
$\mathrm{SR}^{6}$ & 58 \\
\hline${ }^{\mathrm{a}}$ Labels refer to the diastereoisomer in which a particular geometry \\
occurs (see text). See Fig. 2 for labelling. \\
${ }^{\mathrm{b}}$ Relative energy.
\end{tabular}

$\mathrm{SS}^{5}<\mathrm{RS}^{6} \approx \mathrm{SS}^{6}<\mathrm{RR}^{6}<\mathrm{SR}^{6}$, close to the trend in the relative energies of the complexes (see above).

On warming, the ${ }^{1} \mathrm{H}$ NMR signals display reversible band broadening, due to a dynamic process that leads to the interconversion of diastereoisomers $(\mathbf{B})$ and $(\mathbf{C})$ (see Table 2 for labelling). There are three possible exchange pathways, namely a flip of the co-ordinated acetal ring, the tick-tock exchange of pendant and co-ordinated acetal rings and the rotational exchange of pendant and co-ordinated acetal rings $[4,5,8]$. Although these pathways are distinguishable by their different effects on the NMR lineshapes in the intermediate exchange regime, the uncertainty in the spectral assignment frustrated a full and unambiguous analysis of the spin problem. The barrier for the exchange process was estimated from selective inversion experiments, and found to be ca. 79 $\mathrm{kJ} \mathrm{mol}^{-1}$ (there is no significant halogen dependence). For either the tick-tock or rotation processes to be observed, at least one Re-dioxanyl species would need to be evidenced in the NMR spectrum, which the DFT calculations indicate to be unlikely (see above). The dynamic process was therefore assigned tentatively to the acetal ring flip fluxion: the energy barrier measured is close to that observed for the ring flip fluxion in the analogous complexes of $\mathrm{L}^{1}$ (Table 6).

Table 6

Summary of fluxional energetics in the complexes $\left[\mathrm{ReX}(\mathrm{CO})_{3} \mathrm{~L}\right]\left(\mathrm{X}=\mathrm{Cl}, \mathrm{Br} \text { or } \mathrm{I} ; \mathrm{L}=\mathrm{L}^{1}, \mathrm{~L}^{2}, \mathrm{~L}^{3} \text { or } \mathrm{L}^{4}\right)^{\mathrm{a}}$

\begin{tabular}{|c|c|c|c|c|c|c|c|c|}
\hline \multirow[t]{2}{*}{ Halide } & \multicolumn{4}{|c|}{$\Delta G^{\ddagger}$ (acetal ring flip) $\left(\mathrm{kJ} \mathrm{mol}^{-1}\right)$} & \multicolumn{4}{|c|}{$\Delta G^{\ddagger}$ (tick-tock exchange) $\left(\mathrm{kJ} \mathrm{mol}^{-1}\right)$} \\
\hline & {$\left[\operatorname{ReX}(\mathrm{CO})_{3} \mathrm{~L}^{1}\right]$} & {$\left[\operatorname{ReX}(\mathrm{CO})_{3} \mathrm{~L}^{3}\right]$} & {$\left[\operatorname{ReX}(\mathrm{CO})_{3} \mathrm{~L}^{2}\right]$} & {$\left[\operatorname{ReX}(\mathrm{CO})_{3} \mathrm{~L}^{4}\right]$} & {$\left[\mathrm{ReX}(\mathrm{CO})_{3} \mathrm{~L}^{1}\right]$} & {$\left[\operatorname{ReX}(\mathrm{CO})_{3} \mathrm{~L}^{3}\right]$} & {$\left[\mathrm{ReX}(\mathrm{CO})_{3} \mathrm{~L}^{2}\right]$} & {$\left[\operatorname{ReX}(\mathrm{CO})_{3} \mathrm{~L}^{4}\right]$} \\
\hline \multirow{2}{*}{ Chloride } & 77 & 88 & $\mathrm{~b}$ & 82 & 72 & $\mathrm{c}$ & 79 & $\mathrm{c}$ \\
\hline & $\mathrm{b}$ & 84 & b & 81 & $\mathrm{~b}$ & c & $\mathrm{b}$ & $\mathrm{c}$ \\
\hline \multirow[t]{2}{*}{ Bromide } & 77 & 87 & $\mathrm{~b}$ & 81 & 72 & $\mathrm{c}$ & 77 & $\mathrm{c}$ \\
\hline & $\mathrm{b}$ & 86 & $\mathrm{~b}$ & 81 & $\mathrm{~b}$ & $\mathrm{c}$ & $\mathrm{b}$ & $\mathrm{c}$ \\
\hline \multirow[t]{2}{*}{ Iodide } & 78 & 85 & $\mathrm{~b}$ & 78 & 73 & $\mathrm{c}$ & 75 & $\mathrm{c}$ \\
\hline & $\mathrm{b}$ & $\mathrm{b}$ & $\mathrm{b}$ & 81 & $\mathrm{~b}$ & $\mathrm{c}$ & $\mathrm{b}$ & c \\
\hline
\end{tabular}

\footnotetext{
${ }^{a}$ Data published in [4,5] and [8].

${ }^{\mathrm{b}}$ Not all fluxional processes are measurable due to the different diastereoisomer populations.

${ }^{\mathrm{c}}$ The tick-tock fluxion does not occur in complexes of $\mathrm{L}^{3}$ or $\mathrm{L}^{4}$.
} 


\section{Discussion}

Table 6 summarises the activation energies for the 237 acetal-ring flip and tick-tock exchange processes in the 238 tricarbonylhalogenorhenium(I) complexes of $\mathrm{L}^{1}-\mathrm{L}^{4}$. 239 Data show that substitution of the dioxolanyl ligands 240 with the dioxanyl ligands has opposite effects on the 241 energy barriers: $\Delta G^{\ddagger}$ (ring flip) decreases, while $\Delta G^{\ddagger}$ 242 (tick-tock) increases. This observation was difficult to 243 rationalise and led to the study reported here. It was 244 believed initially [5] that the ground-state energy was 245 lower in the dioxanyl complexes. The DFT calculations 246 indicate clearly that this is not the case: binding of 247 dioxolanyl ring in $\left[\mathrm{ReX}(\mathrm{CO})_{3} \mathrm{~L}^{\mathrm{HH}}\right]$ is favoured by ca. $24812-50 \mathrm{~kJ} \mathrm{~mol}^{-1}$. The lower ground state energy in the 249 dioxolanyl complexes presumably accounts for the in250 creased barrier to the ring flip process.

251 The lower ground state energy of the dioxolanyl 252 complexes may also be expected to result in an increase 253 in the barrier to the tick-tock exchange fluxion, which is 254 not the case. Thus the decrease in the barrier to the tick255 tock exchange fluxion that occurs when $\mathrm{L}^{2}$ is substituted 256 with $\mathrm{L}^{1}$ must be the result of a greater stabilisation of 257 the transition state energy. This stabilisation arises 258 presumably because of the more favourable Re-diox259 olanyl interactions in the transition state, in which the 260 ligand is bound to the metal centre in a pseudo-terden261 tate fashion [4,5].

\section{4. Experimental}

\section{4.1. Synthetic methods}

264 All procedures were carried out using standard 265 Schlenk techniques under an atmosphere of dry, oxygen266 free nitrogen. Solvents were dried by distillation from 267 appropriate drying agents [12] and stored under nitro268 gen. Starting materials were purchased from standard 269 sources. The $\left[\operatorname{ReX}(\mathrm{CO})_{5}\right](\mathrm{X}=\mathrm{Cl}, \mathrm{Br}$ or I) compounds 270 were prepared by previously published procedures [13]. 271 The non-racemic chiral acetal ligand 2-[(4R,5R)-4,5272 dimethyl-1,3-dioxolan-2-yl]-6-[(4R,6R)-4,6-dimethyl-1,3273 dioxan-2-yl]pyridine $\left(\mathrm{L}^{\mathrm{HH}}\right)$ was synthesised in a stepwise 274 fashion from 2,6-dibromopyridine, as detailed below. $275 \mathrm{~L}^{\mathrm{HH}}$ can be prepared via either route (i) or route (ii) 276 (Scheme 1). The former pathway is the economically 277 preferred route because, during preparation of (3a) or 278 (3b), the acetal group reacts with hydrochloric acid, which 279 is used in the work-up, to yield 2,6-pyridinedicarboxal280 dehyde: $(4 R, 6 R)$-pentanediol is the more expensive diol.

\section{4.1.1. 6-Bromopyridine-2-aldehyde (1)}

282 6-Bromopyridine-2-aldehyde was prepared using a 283 procedure adapted from that previously published [14].
To a slurry of $10.0 \mathrm{~g}(0.042 \mathrm{~mol})$ of 2,6-dibromopyridine in $250 \mathrm{~cm}^{3}$ of cold $\left(-80{ }^{\circ} \mathrm{C}\right)$ diethyl ether, $27.0 \mathrm{~cm}^{3}$ of 1.6 $\mathrm{M}$ of $n$-butyllithium in hexanes was added dropwise. After the addition was complete, the reaction mixture was allowed to warm to $-40{ }^{\circ} \mathrm{C}$; a clear yellow solution resulted. This solution was cooled to $-80{ }^{\circ} \mathrm{C}$ and $7 \mathrm{~cm}^{3}$ $(0.084 \mathrm{~mol})$ of $\mathrm{N}, \mathrm{N}$-dimethylformamide in diethyl ether $\left(20 \mathrm{~cm}^{3}\right)$ was added slowly. The reaction was stirred at $-70{ }^{\circ} \mathrm{C}$ for $2 \mathrm{~h}$, during which time a white solid precipitated. The mixture was allowed to warm to $-10{ }^{\circ} \mathrm{C}$ and hydrolysed with $10 \mathrm{~cm}^{3}$ of concentrated hydrochloric acid. The aqueous phase was separated and extracted with diethyl ether. The extracts and ether phase were combined, washed with water, dried over magnesium sulfate, and evaporated to dryness. Crystallisation of the solid residue from a diethyl ether $/ n$-pentane mixture gave $5.94 \mathrm{~g}(76 \%)$ of pure (1).

\subsubsection{2-[(4R,5R)-dimethyl-1,3-dioxolan-2-yl]-6-Bromo- pyridine (2a)}

$1(5.0 \mathrm{~g}, 0.027 \mathrm{~mol}),(2 R, 3 R)$-butanediol $\left(2.7 \mathrm{~cm}^{3}\right.$, $0.030 \mathrm{~mol}), 2,2$-dimethoxypropane $\left(3.7 \mathrm{~cm}^{3}, 0.030 \mathrm{~mol}\right)$, and para-toluenesulfonic acid (ca. $100 \mathrm{mg}$ ) were refluxed for $18 \mathrm{~h}$ in $30 \mathrm{~cm}^{3}$ of benzene. The resulting solution was extracted with aqueous sodium carbonate solution $\left(3 \times 30 \mathrm{~cm}^{3}\right)$ then water $\left(3 \times 30 \mathrm{~cm}^{3}\right)$, dried over magnesium sulfate, and concentrated to dryness in vacuo. The solid residue was crystallised from hot hexane, yielding pure (2a). Yield: $3.6 \mathrm{~g}(52 \%)$.

\subsubsection{2-[(4R,5R)-dimethyl-1,3-dioxolan-2-yl]-6-Alde-} hydepyridine $(\mathbf{3 a})$

2-[(4R,5R)-dimethyl-1,3-dioxolan-2-yl]-6-Aldehydepyridine was prepared using a similar procedure to that for (1). Yield: $38 \%$.

4.1.4. 2-[(4R,5R)-dimethyl-1,3-dioxolan-2-yl]-6-[(4R,6R)4,6-dimethyl-1,3-dioxan-2-yl]Pyridine $\left(L^{\mathrm{HH}}\right)$

3a $(0.80 \mathrm{~g}, 3.86 \mathrm{mmol}),(4 R, 6 R)$-pentanediol $(0.41 \mathrm{~g}$, $3.90 \mathrm{mmol}), 2$ 2,2-dimethoxypropane $\left(0.48 \mathrm{~cm}^{3}, 3.90\right.$ $\mathrm{mmol}$ ), and para-toluenesulfonic acid (ca. $100 \mathrm{mg}$ ) were refluxed for $72 \mathrm{~h}$ in $30 \mathrm{~cm}^{3}$ of toluene. The resulting solution was extracted with aqueous sodium carbonate solution $\left(3 \times 30 \mathrm{~cm}^{3}\right)$ then water $\left(3 \times 30 \mathrm{~cm}^{3}\right)$, dried over magnesium sulfate, and concentrated to dryness in vacuo. The residue was crystallisation from hot petroleum ether to yield $0.71 \mathrm{~g}(63 \%)$ of $\mathrm{L}^{\mathrm{HH}}$.

\subsection{Physical methods}

${ }^{1} \mathrm{H},{ }^{13} \mathrm{C}$ and ${ }^{2} \mathrm{H}$ NMR spectra were recorded on a Bruker DRX500 Fourier transform spectrometer operating at 500.13, 125.75 and $76.77 \mathrm{MHz}$, respectively. Chemical shifts are quoted relative to tetramethylsilane. Probe temperatures were controlled by a standard B-VT 
2000 unit and are considered accurate to $\pm 1 \mathrm{~K}$. Spinlattice relaxation times, and COSY and NOESY spectra were obtained using the standard Bruker automation programs T1IR, COSYST and NOESYST, respectively. Selective inversion experiments were carried out using our SOFTPULVD program, which generates the pulse se-

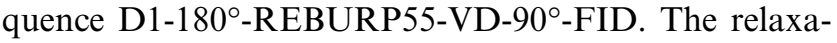
tion delay was $25 \mathrm{~s}$ and the VD list typically contained 20 delays. Exchange rates were extracted from the longitudinal magnetisations using the program CIFIT [15].

Infrared spectra were recorded in $\mathrm{CH}_{2} \mathrm{Cl}_{2}$ solution on a Shimadzu hyper 8700 FT-IR spectrometer operating in the region $4000-400 \mathrm{~cm}^{-1}$. Fast atom bombardment mass spectra were obtained at the London School of Pharmacy on a VG Analytical ZAB-SE4F instrument, using $\mathrm{Xe}^{+}$bombardment at $8 \mathrm{kV}$ energy, on samples in a matrix of 3-nitrobenzyl alcohol. Elemental analyses were carried out at University College London.

\subsection{Computations}

The initial free ligand geometric structure was constructed using the Molden molecular modelling software [16] using fragments taken from the Cambridge Crystallographic Database. A DFT/B3LYP [17] geometry optimisation was performed, without symmetry constraints $\left(6-31 \mathrm{G}^{* *}\right.$ basis set), using GAMESS-UK version 6.2 [18]. In order to check the conformational stability of the ligands when bound to the metal centre a number of additional calculations were performed. These compared the geometry of the bound ligand (see below) to that of the optimised free ligand. Calculations were again performed with GAMESS-UK using a $6-31 \mathrm{G}^{* *}$ basis-set at the DFT/B3LYP level of theory.

Calculations on the complexes were performed using the Amsterdam Density Functional program suite [1923]. An uncontracted double-zeta Slater-type orbital valence basis set, supplemented with a $p$ function for hydrogen and a d polarisation function for carbon, nitrogen, oxygen and chlorine (ADF Type III), was employed for the non-metallic elements. For Re, the ADF Type IV basis set, which may be described as triple-zeta without polarisation functions was used. Scalar relativistic corrections [24] were included via the ZORA to the Dirac equation $[25,26]$. The frozen core approximation was employed. The relativistic frozen cores (calculated by the ADF auxiliary program Dirac) used were: carbon (1s), nitrogen (1s), oxygen (1s), chlorine (2p) and rhenium (4f). The local density parameterisation of Vosko et al. [27] was employed, in conjunction with Becke's gradient correction [28] to the exchange part of the potential and the correlation correction of Perdew [29]. The default integration parameter of 4.0 was used in all calculations. Geometry optimisations were conducted without symmetry constraints, using a gradient convergence criterion of $0.005 \mathrm{au} / \mathrm{A}$.

\section{Acknowledgements}

We are grateful to The Royal Thai Government for a studentship (P.S.) and to Johnson Matthey for the loan of rhenium.

\section{References}

[1] A.H. Ghosh, P. Mathivanan, J. Cappiello, Tetrahedron Asymmetr. 9 (1998) 1.

[2] P.J. Heard, C. Jones, J. Chem. Soc., Dalton Trans. (1997) 1083.

[3] P.J. Heard, D.A. Tocher, J. Chem. Soc., Dalton Trans. (1998) 2169.

[4] P.J. Heard, A.D. Bain, P. Hazendonk, D.A. Tocher, J. Chem. Soc., Dalton Trans. (1999) 4495.

[5] P.J. Heard, P.M. King, D.A. Tocher, J. Chem. Soc., Dalton Trans. (2000) 1769.

[6] gNMR v4.1.0, Cherwell Scientific Limited, Oxford, 2000.

[7] P. Sroisuwan, PhD Thesis, University of London, 2002.

[8] P.J. Heard, A.D. Bain, P. Hazendonk, Can. J. Chem. 77 (1999) 1707.

[9] D.A. Edwards, J. Marshalsea, J. Organomet. Chem. 131 (1977) 73.

[10] R.F.W. Bader, J.R. Cheeseman, K.E. Laidig, K.B. Wiberg, C. Breneman, J. Am. Chem. Soc. 112 (1990) 6530.

[11] E.L. Eliel, S.H. Wilen, Stereochemistry of Organic Compounds, Wiley, New York, 1994.

[12] D.D. Perrin, W.L.F. Armarego, Purification of Laboratory Chemicals, Pergamon, Oxford, 1988.

[13] P. Schmidt, W.C. Trogler, F. Basolo, Inorg. Synth. 28 (1979) 160

[14] J.E. Parks, B.E. Wagner, R.H. Holm, Inorg. Chem. 10 (1971) 2472.

[15] A.D. Bain, J.A. Cramer, J. Magn. Reson. A 118 (1996) 21

[16] G. Schaftenaar, J.H. Noordik, Molden: a pre- and post-processing program for molecular and electronic structures, J. Comput.Aided Mol. Des. 14 (2000) 123.

[17] A.D. Becke, J. Chem. Phys. 98 (1993) 5648

[18] GAMESS-UK version 6.2, CFS Ltd., CCLRC Daresbury Laboratory, 1999. GAMESS-UK is a package of ab initio programs by M.F. Guest, J.H. van Lenthe, J. Kendrick, K. Schoffel and P. Sherwood, with contributions from R.D. Amos, R.J. Buenker, H.J.J. van Dam, M. Dupuis, N.C. Handy, I.H. Hillier, P.J. Knowles, V. Bonacic-Koutecky, W. von Niessen, R.J. Harrison, A.P. Rendell, V.R. Saunders, A.J. Stone and A.H. de Vries. The package is derived from the original GAMESS code of M. Dupuis, D. Spangler and J. Wendoloski, NRCC Software Catalog, vol. 1, Program No. QG01 (GAMESS), 1980.

[19] ADF2000, Department of Theoretical Chemistry, Vrije Universiteit, Amsterdam, 2000.

[20] E.J. Baerends, D.E. Ellis, P. Ros, Chem. Phys. 2 (1973) 41.

[21] L. Versluis, T. Ziegler, J. Chem. Phys. 88 (1988) 322.

[22] G. te Velde, E.J. Baerends, J. Comp. Phys. 99 (1992) 84.

[23] C. Fonseca Guerra, J.G. Snijders, G. te Velde, E.J. Baerends, Theor. Chem. Acc. 99 (1998) 391.

[24] N. Kaltsoyannis, J. Chem. Soc., Dalton Trans. (1997) 1.

[25] E. van Lenthe, R. van Leeuwen, E.J. Baerends, J.G. Snijders, Int. J. Quantum Chem. 57 (1996) 281.

[26] E. van Lenthe, J.G. Snijders, E.J. Baerends, J. Chem. Phys. 105 (1996) 6505.

[27] S.H. Vosko, L. Wilk, M. Nusair, Can. J. Phys. 58 (1980) 1200.

[28] A.D. Becke, Phys. Rev. A 38 (1988) 3098.

[29] J.P. Perdew, Phys. Rev. B 33 (1986) 8822.
393

394

395

396

397

398

399

400

401

402

403

404

405

406

407

408

409

410

411

412

413

414

415

416

417

418

419

420

421

422

423

424

425

426

427

428

429

430

431

432

433

434

435

436

437

438

439

440

441

442

443

444

445

446

447 